\title{
A method for determining the content of petroleum hydrocarbons
}

\author{
in soil \\ Haitian Qin, He Huang* \\ Yangtze University, School of Chemistry and Environmental Engineering, \\ 1 Nanhuan Road, Jingzhou District, Jingzhou City, Hubei Province, China \\ He Huang@105367750@qq.com
}

\begin{abstract}
:
In this paper, ultrasonic-centrifugal extraction-infrared petroleum meter is used to determine petroleum hydrocarbons in soil. The optimal conditions of ultrasonic centrifugal extraction of petroleum hydrocarbons from soil were investigated by using simulated soil from the extraction agent, ultrasonic temperature, ultrasonic time, ultrasonic power, centrifugal speed, centrifugal time and other factors. The results showed that using tetrachloroethylene as extraction agent, the extraction efficiency of three times reached $88.34 \%$ with ultrasonic temperature of $30^{\circ} \mathrm{C}$, ultrasonic time of $10 \mathrm{~min}$, ultrasonic power of $180 \mathrm{~W}$, centrifugal speed of 4000rpm and centrifugation time of $20 \mathrm{~min}$ in $1 \%$ petroleum-contaminated soil.Under these conditions, the recoveries were $78.97 \%$ 96.58\% and the relative standard deviations $(\mathrm{n}=5)$ of the measured values were $3.82 \% \sim 12.53 \%$.
\end{abstract}

Key words: Petroleum hydrocarbon; Ultrasonic-centrifugal extraction; Soil; Infrared petroleum meter.

\section{Introduction}

With the increase of petroleum usage, petroleum hydrocarbon polluted soil has been concerned by all circles of society. It is essential to find an efficient and rapid petroleum hydrocarbon detection method in order to accu- rately understand the oil contaminated soil. Detection of petroleum hydrocarbons in soil with traditional Soxhlet extraction often takes a long time ${ }^{[1,2]}$. In order to save cost and improve efficiency, this paper adopts ultrasonic-centrifugal method to extract petroleum hydroca-rbons from soil, and uses infrared petroleum meter to accurately measure the content of petroleum hydrocarbons, and optimates the experimental conditions.

\section{Experiment}

\subsection{Experimental materials}

The soil used in the experiment was simulated petroleum-contaminated soil: the origi- nal soil was collected from the forest on the campus of Yangtze University, and the unpolluted sandy loam with a depth of $20 \sim 50 \mathrm{~cm}$. The soil was air-dried, screened and reserved. Soil basic properties: water content $0.25 \%, \mathrm{pH}=7.86$, organic matter content $1.17 \% .1 .00000 \mathrm{~g}$ of petroleum was accurately weighed in a beaker, completely dissolved with petroleum ether $\left(30 \sim 60^{\circ} \mathrm{C}\right)$, and poured into the above soil to make petroleum-contaminated soil with a pollu- tion concentration of $1 \%$.

Experimental drugs dichloromethane, petro- leum ether, anhydrous sodium sulfate are analytical pure, carbon tetrachloride, tetrachlo- roethylene for infrared spectrum pure, tetra- chloroethylene in the petroleum solution standard material purchased from Beijing Shengshipu Chemical Technology Research Institute.

The main experimental instruments are Oil510 infrared spectrometer petroleum mea- suring instrument (Beijing Huaxia Kechuang), 
KQ-300DE numerical control ultrasonic cleaner (Kunshan Ultrasonic Instrument Co., Ltd.), LD-3 electric centrifuge (Jiangsu Jantan Jincheng Guosheng Experimental Instrument Factory), DV215CD electronic balance (sensing capacity $0.01 \mathrm{mg}$, Aohaus Instrument Co., Ltd.). In the experiment, the glass instrument needs to be soaked and washed with chromic acid solution.

\subsection{Experimental method}

\subsubsection{Selection of extractant}

Weighed $1 \mathrm{~g}$ of contaminated soil into a $50 \mathrm{ml}$ centrifuge tube, accurately recorded the soil mass $\mathbf{m}$ (accurate to $0.01 \mathrm{mg}$ ), and added an appropriate amount of anhydrous sodium sulfate to remove the moisture in the soil. $5 \mathrm{~mL}$ of the extractant was added, followed by ultrasonic extraction $\left(30^{\circ} \mathrm{C}, 10 \mathrm{~min}\right.$, $300 \mathrm{w}$ )-centrifugation (3000rpm, 10min) and then the supernatant was collected in a clean small beaker. The supernatant was combined with the extraction for three times, and the petroleum hydrocarbons in the small beakers were trans- ferred to a $25 \mathrm{~mL}$ volumetric flask with tetrach- loroethylene. The extraction solution was diluted (n times) as needed, and the concentration of $\mathbf{c}_{\mathbf{1}}$ was detected with an infrared petroleum meter, and then the content of petroleum hydrocarbons in the soil was determined according to Equation (1). If there are impurities in the extraction solution, it is necessary to use silica adsorption column to purify $\mathrm{it}^{[3]}$. Three parallel samples were made for each group of experiments.

The extraction agents were selected as tetrachloroethylene, dichloromethane, carbon tetrachloride and petroleum ether to investigate the effects of different extraction agents on recovery.

$$
w=\frac{0.025 \times \mathrm{n} \times \mathrm{c}_{1}}{1000 \times \mathrm{m}} \times 100 \%
$$

w: the content of petroleum hydrocarbons in soil, $\%$; $\mathbf{n}$ : the dilution ratio of extraction liquid;

$\mathbf{c}_{1}$ : the concentration detected by the infrared petroleum meter of the diluted extraction solution, $\mathrm{mg} / \mathrm{L}$;

m: the mass of soil sample, g.
Ultrasonic-centrifugal extraction is an effi- cient and rapid extraction method of petroleum pollutants by using the cavitation effect and centrifugal separation effect caused by ul- trasound. The power and time of ultrasonic extraction had positive effects on extraction efficiency ${ }^{[4]}$, Centrifugation can separate solid and liquid. Under the extraction conditions, ultrasonic temperature, ultrasonic power, ultrasonic time, centrifugal speed and centrifugal time were selected as test factors, and $\mathrm{L}_{16}\left(4^{5}\right)$ was used to design the orthogonal experiment (Table 1).

Table 1: Orthogonal experimental design

\begin{tabular}{|l|l|l|l|l|l|}
\hline & A & B & C & D & E \\
\hline Level 1 & 20 & 120 & 5 & 1000 & 5 \\
\hline Level 2 & 30 & 180 & 10 & 2000 & 10 \\
\hline Level 3 & 40 & 240 & 15 & 3000 & 15 \\
\hline Level 4 & 50 & 300 & 20 & 4000 & 20 \\
\hline
\end{tabular}

A:ultrasonic temperature $\left({ }^{\circ} \mathrm{C}\right)$

B:ultrasonic power ( $\mathrm{w}$ )

C:ultrasonic time $(\mathrm{min})$

D:centrifugal speed (rpm)

E:centrifugal time $(\min )$

\subsubsection{Determination of soil petroleum recovery}

Soil samples with petroleum concentration of $0.5 \%, 1 \%, 1.5 \%, 2 \%$ and $2.5 \%$ were prepared according to the method of soil preparation in 1.1, respectively, and were extracted under the optimal extraction conditions obtained from orthogonal experiment. The content of petroleum hydrocarbons in the soil was detected and calculated with an infrared petroleum meter. The recovery rate is calculated according to Equation (2).

$$
\text { Recovery } \%=\frac{\mathrm{w}}{w_{0}} \times 100 \%
$$

w: the content of petroleum hydrocarbons in the soil, \%;

$\mathbf{w}_{\mathbf{0}}$ : the content of petroleum hydrocarbons in simulated soil, $\%$.

\section{Result and discussion}

\subsubsection{Orthogonal experimental design}


3.1 Influence of different extractants on the determination of petroleum hydrocarbons in soil According to the principle of "similar phase solution" and the extraction agents selected for the detection of petroleum hydrocarbons at home and abroad, four extraction agents including tetrachloroethylene, carbon dichloride, carbon tetrachloride and petroleum ether were selected to extract petroleum hydrocarbons in the soil in the experiment, and Figure 1 was obtained. It can be seen from Figure 1 that the highest detection recovery rate after extraction was carbon tetrachloride $(84.23 \%)$, while the lowest was carbon dichloride.In Coulon's study, the extraction efficiency could reach 95\% 99\% by using flared ultrasound, and in this experiment, the maximum extraction efficiency was $88.23 \%$ for three times, which may be caused by different ultrasonic forms ${ }^{[4]}$. The extraction efficiency of petroleum ether was $63.28 \%$. Considering the toxicity of carbon tetrachloride, this experiment uses tetrachloroethylene as extraction agent, because the extraction efficiency of tetrachloroethylene is $80.65 \%$, second only to carbon tetrachloride. The selection of tetrachloroethylene as extraction agent in the experiment can not only reduce the amount of extraction agent, but also reduce the experimental step of evaporation and concentration, simplify the experimental steps and save the detection time. Therefore, in the subsequent experiments, tetrachloroethylene was used as the extractant.

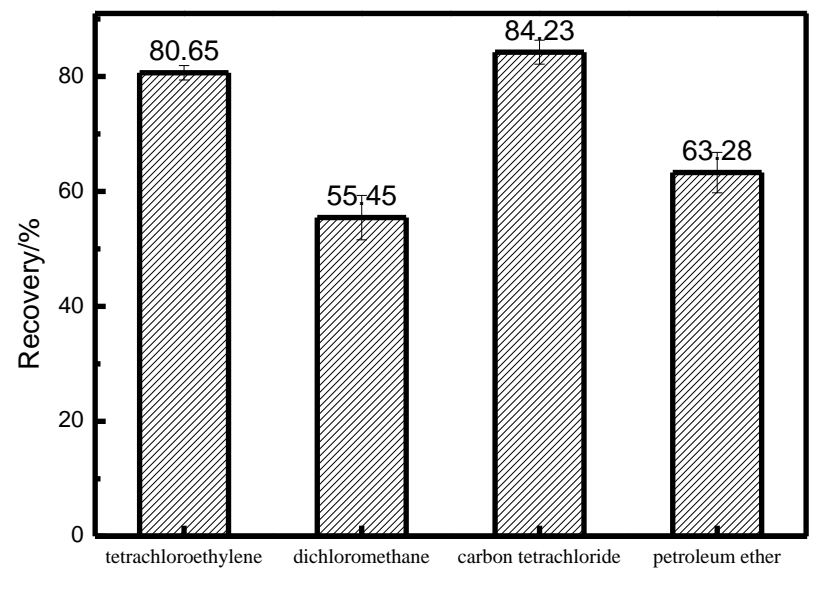

Extractant

Figure 1: Influence of different extractant on recovery rate

\subsection{Analysis of orthogonal experiment results}

According to orthogonal experimental analysis(Table 2), the extraction influence factors can be obtained: ultrasonic temperature > ultrasonic time > centrifugal time > ultrasonic power > centrifugal speed.

Table 2 Results of orthogonal experiment

\begin{tabular}{|c|c|c|c|c|c|c|}
\hline & $\mathrm{A}$ & $\mathrm{B}$ & $\mathrm{C}$ & $\mathrm{D}$ & $\mathrm{E}$ & Recovery (\%) \\
\hline 1 & $1(20)$ & $1(120)$ & $1(5)$ & $1(1000)$ & $1(5)$ & 59.03 \\
\hline 2 & $1(20)$ & $2(180)$ & $2(10)$ & $2(2000)$ & $2(10)$ & 75.56 \\
\hline 3 & $1(20)$ & $3(240)$ & $3(15)$ & $3(3000)$ & $3(15)$ & 66.87 \\
\hline 4 & $1(20)$ & $4(300)$ & $4(20)$ & $4(4000)$ & $4(20)$ & 81.26 \\
\hline 5 & $2(30)$ & $1(120)$ & $2(10)$ & $3(3000)$ & $4(20)$ & 88.31 \\
\hline 6 & $2(30)$ & $2(180)$ & $1(5)$ & $4(4000)$ & $3(15)$ & 79.04 \\
\hline 7 & $2(30)$ & $3(240)$ & $4(20)$ & $1(1000)$ & $2(10)$ & 79.88 \\
\hline 8 & $2(30)$ & $4(300)$ & $3(15)$ & $2(2000)$ & $1(5)$ & 85.50 \\
\hline 9 & $3(40)$ & $1(120)$ & $3(15)$ & $4(4000)$ & $2(10)$ & 64.62 \\
\hline 10 & $3(40)$ & $2(180)$ & $4(20)$ & $3(3000)$ & $1(5)$ & 71.70 \\
\hline 11 & $3(40)$ & $3(240)$ & $1(5)$ & $2(2000)$ & $4(20)$ & 62.36 \\
\hline 12 & $3(40)$ & $4(300)$ & $2(10)$ & $1(1000)$ & $3(15)$ & 64.97 \\
\hline 13 & $4(50)$ & $1(120)$ & $4(20)$ & $2(2000)$ & $3(15)$ & 65.94 \\
\hline 14 & $4(50)$ & $2(180)$ & $3(15)$ & $1(1000)$ & $4(20)$ & 74.86 \\
\hline 15 & $4(50)$ & $3(240)$ & $2(10)$ & $4(4000)$ & $1(5)$ & 75.89 \\
\hline 16 & $4(50)$ & $4(300)$ & $1(5)$ & $3(3000)$ & $2(10)$ & 61.71 \\
\hline $\mathrm{k} 1$ & 70.68 & 69.48 & 67.87 & 69.69 & 73.03 & \\
\hline
\end{tabular}




\begin{tabular}{|c|c|c|c|c|c|c|}
\hline $\mathrm{k} 2$ & 83.18 & 75.29 & 76.18 & 72.34 & 70.44 & \\
\hline $\mathrm{k} 3$ & 65.91 & 71.25 & 72.96 & 72.15 & 69.21 & \\
\hline $\mathrm{k} 4$ & 69.60 & 73.36 & 72.36 & 75.20 & 76.70 & \\
\hline Range & 17.27 & 5.81 & 8.32 & 5.51 & 7.49 & \\
\hline Order & \multicolumn{7}{|c|}{ A $>$ C > $>$ B $>$ D } \\
\hline Choice & A2 & B2 & C2 & D4 & E4 & \\
\hline Optimization & \multicolumn{7}{|c|}{} \\
\hline
\end{tabular}

The optimal extraction conditions were as follows: ultrasonic temperature of $30^{\circ} \mathrm{C}$, ul- trasonic power of $180 \mathrm{~W}$, ultrasonic time of $10 \mathrm{~min}$, centrifugal speed of $4000 \mathrm{rpm}$, and centrifugal time of $20 \mathrm{~min}$. Under these conditions, the extraction efficiency of petroleum-contaminated soil with $1 \%$ pollution concentration was about $88.34 \%$.

The influences of various factors on ex- traction effect are as follows:

The effect of ultrasonic temperature on the recovery rate is shown in Figure 2(a): from $20^{\circ} \mathrm{C}$ to $30^{\circ} \mathrm{C}$, the extraction efficiency of petroleum hydrocarbons in the soil increases by about $13 \%$. This is because the viscosity of petroleum decreases with the increase of temperature, and the binding ability of petroleum to the soil also decreases, making it easier for petroleum molecules to break off from the surface of soil particles and enter the extractant.The extraction efficiency decreases when the temperature increases from $30^{\circ} \mathrm{C}$ to $50^{\circ} \mathrm{C}$.

According to the relationship between ultrasonic cavitation and temperature, it can be known that when the temperature is too high, the cavitation is weakened, which is not conducive to the extraction of petroleum. In the experimental study of Zhou Wuju ${ }^{[5]}$, when the temperature was $22-50^{\circ} \mathrm{C}$, the extraction efficiency also showed a trend of first rising and then falling, which was relatively stable on the whole. The temperature over $60^{\circ} \mathrm{C}$ would cause petroleum loss and affect the accuracy of the results.

The influence of ultrasonic power on recovery as shown in figure. 2(b): along with the change of the ascension of the ultrasonic power recovery trend and the trend of temperature elevation was similar, because the power of ascension makes energy increases, can make petroleum hydrocarbon separated from soil, but high power become more small, can make the soil particle breaking increase soil particles on the adsorption effect of petroleum hydrocarbon, so that the lower the recovery. It was probably the reason that the cavitation bubbles in a greater ultrasonic intensity tended to grow too big to collapse or collapse weakly, which may result in the reduction of cavitation effect ${ }^{[6]}$. Therefore, appropriate ultrasonic power is helpful to improve the recovery rate.

The effect of ultrasonic time on recovery was shown in Figure. 2(c): with the increase of ultrasonic time, extraction efficiency first increased and then decreased. According to the damage of the bonding force of oil and soil by ultrasonic wave, the increase of time helps the petroleum to detach from the soil surface and enter the extractant. However, the energy of ultrasonic wave will not only destroy the binding force of petroleum-soil, but also break the soil particles into finer particles, increase the adsorption capacity of the soil particles to petroleum hydrocarbons $^{[7]}$, and reverse adsorption will be carried out on the released petroleum, thus reducing the extraction efficiency.

The influence of centrifugal speed on recovery is shown in Figure. 2(d): the higher the centrifugal speed, the higher the recovery. The main function of centrifugation is to separate the solid and liquid phases. During the ultrasonic process, petroleum hydrocarbons in the soil were fully mixed with the extractant, and some petroleum hydrocarbons were transferred to the extractant. However, the solution after the ultrasound was very turbid. In order to reduce the detection time, centrifugal method was used to make the solid-liquid two-phase separation quickly. With the increase of centrifugal speed, the 
solid-liquid separation is more complete and the recovery rate is also increased.

The effect of centrifugation time on recovery was shown in Figuer2(e): with the increase of centrifugation time, recovery firstly decreased and then increased.The increase of centrifugation time can make the solid-liquid separation more complete, which should improve the recovery rate. However, this rule is not obvious in the experiment, because various factors in the orthogonal experiment may interact with each other, resulting in a difference between the results and the separate analysis.
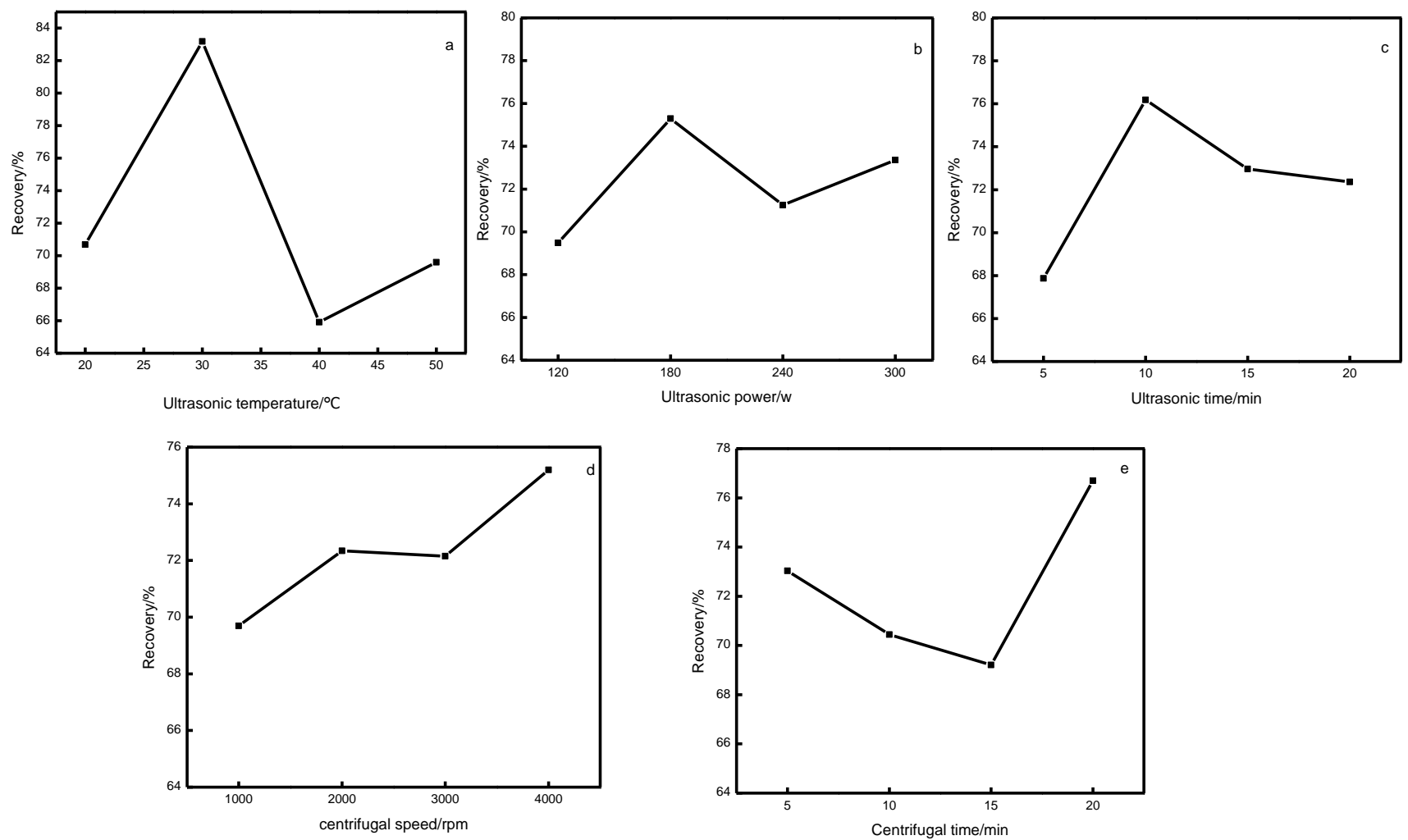

Figure 2: Result of orthogonal experiment

\subsection{Comparison of extraction effects of soil with} different pollution concentrations

In the extraction process, the soil sample with a pollution concentration of $0.5 \%$ was nearly colorless in the second extraction, and its chromaticity could not be distinguished by the naked eye in the third extraction, which indicated that the extracted solution contained very little petroleum. As can be seen from Table 3, the recovery rate of petroleum hydrocarbons in the soil reached $96.58 \%$ at this concentration. The recovery rate decreased with the increase of pollutant concentration, but the recovery rate was above $78 \%$. When the pollution concentration is $1 \%$, the recovery rate of petroleum hydrocarbons in the soil is about $84.59 \%$, which is decreased compared with $88.34 \%$ in the orthogonal experiment, which may be related to the time of pollution and the degradation of petroleum hydrocarbons in the soil itself.In addition, judging the approximate pollution concentration according to the color depth of the extracted solution, multiple extraction can improve the recovery rate. Therefore, it is necessary to appropriately increase the extraction times according to the color of the extracted solution in the extraction process to make the result more accurate.

Table 3 extraction results of soil with different pollution concentrations $(n=5)$

\begin{tabular}{|c|c|c|c|}
\hline $\begin{array}{c}\text { Petroleum } \\
\text { pollution } \\
\text { concentration }\end{array}$ & Mean & Recovery & RSD \\
detion & $\%$ & $\%$ \\
& $\%$ & & \\
\hline
\end{tabular}




\begin{tabular}{|c|c|c|c|}
\hline 0.5 & 0.4829 & 96.58 & 12.53 \\
\hline 1.0 & 0.8459 & 84.59 & 4.39 \\
\hline 1.5 & 1.2133 & 80.89 & 9.78 \\
\hline 2.0 & 1.6121 & 80.61 & 3.82 \\
\hline 2.5 & 1.9743 & 78.97 & 8.24 \\
\hline
\end{tabular}

When extraction times were 5 times, the recovery rate was significantly improved (Table 4). Because according to the Nernst distribution law, the increase of extraction times can effectively improve the extraction efficiency. However, the increase of extraction times requires longer detection time and more detection reagents, so we need to appropriately increase extraction times according to the actual situation.

Table 4 extraction results of soil with different pollution concentrations $(n=5)$

\begin{tabular}{|c|c|c|c|}
\hline $\begin{array}{c}\text { Petroleum } \\
\text { pollution } \\
\text { concentration } \\
\%\end{array}$ & $\begin{array}{c}\text { Mean } \\
\text { detection } \\
\text { concentration } \\
\%\end{array}$ & $\begin{array}{c}\text { Recovery } \\
\%\end{array}$ & $\begin{array}{c}\text { RSD } \\
\%\end{array}$ \\
\hline 0.5 & 0.5223 & 104.46 & 6.07 \\
\hline 1.0 & 0.9522 & 95.22 & 1.42 \\
\hline 1.5 & 1.3505 & 90.03 & 2.16 \\
\hline 2.0 & 1.7875 & 89.38 & 9.18 \\
\hline 2.5 & 2.1841 & 87.36 & 4.74 \\
\hline
\end{tabular}

If this method is used in the actual soil detection, it should be noted that compared with the simulated soil, the actual soil has longer pollution time, stronger binding ability with petroleum hydrocarbons, and more difficult recovery rate ${ }^{[8]}$. Therefore, in the actual detection process, the extraction times should be appro- priately increased according to soil properties, petroleum types and pollution concentrations.

\section{Conclusion}

It is the best choice to use tetrachloroe- thylene as extraction agent considering toxicity and extraction efficiency when using ultrasonic centrifugal-infrared petroleum measuring instru- ment to detect the content of petroleum hydro- carbons in soil.

The primary and secondary effects of the factors affecting the extraction of petroleum hydrocarbons in the soil are as follows: ultrasonic temperature > ultrasonic time $>$ centrifugal time $>$ ultrasonic power $>$ centrifugal speed. The optimal extraction conditions were as follows: ultrasonic temperature of $30^{\circ} \mathrm{C}$, ultrasonic power of $180 \mathrm{~W}$, ultrasonic time of 10min, centrifugal speed of $4000 \mathrm{rpm}$, centrifugal time of $20 \mathrm{~min}$. Under this condition, the soil recovery rate of $1 \%$ petroleum content is $88.34 \%$.

Under the optimal extraction conditions, the extraction efficiency of the soil with different pollution concentrations was more than $78 \%$. In the process of extraction, the soil with higher concentration needed to increase the extraction times appropriately to make the results more accurate.

\section{References}

[1] Cicero, A., Pietrantonio, E., Romanelli, G. et al. "Comparison of Soxhlet, Shaking, and Microwave Assisted Extraction Techniques for Determination of PCB Congeners in a Marine Sediment," Bull. Environ. Contam. Toxicol,65,pp. 307-313, 2000.

[2] George M. J. ,Sichilongo K. F. Ramabulana T., Madala N. E., Dubery, I. A., "Comparison of Soxhlet and reflux techniques for extraction and characterisation of potential endocrine-disrupting compounds from solid waste dumpsite soil," Environ Monit Assess, 191, pp.149, 2019

[3] Gómez, R.S.G., Pandiyan, T., Iris, V.E.A. et al. "Spectroscopic determination of polyaromatic compounds in petroleum contaminated soils," Water, Air, \& Soil Pollution, 158,pp. 137-151, 2004.

[4] COULON F, WU G. "Determination of Petroleum Hydrocarbon Compounds from Soils and Sediments Using Ultrasonic Extraction," Humana Press, pp.31-46, 2014.

[5] Zhou Wuju. "Experimental study on the determination of petroleum and animal and vegetable oils in soil by ultrasonic extraction and infrared spectrophotometry," Safety and Environmental Engineering, 16, pp.53-53+57, 2009 
[6] Liao, J., Zheng, N. \& Qu, B. "An Improved Ultrasonic-Assisted Extraction Method by Optimizing the Ultrasonic Frequency for Enhancing the Extraction Efficiency of Lycopene from Tomatoes," Food Anal, Methods 9,pp. 2288-2298,2016.

[7] Mat-Shayuti, M., Tuan Ya, T.M.Y.S. et al. "Progress in ultrasonic oil-contaminated sand cleaning: a fundamental review," Environ Sci Pollut Res 26, pp.26419-26438,2019.

[8] KWON M J, LEE G, HWANG Y H, et al. "Effects of Soil Micro-particles and Micropores on Petroleum Hydrocarbons Released From Contaminated Soils During Solvent Extraction with Ultrasound," Water, Air, \& Soil Pollution, 227(9), pp.357,20 